\title{
Using Second Life for Just-in-Time Training: Building Teaching Frameworks in Virtual Worlds
}

\author{
doi:10.3991/ijac.v3i3.1373 \\ Gail Kopp $^{1}$ and Martha Burkle ${ }^{2}$ \\ ${ }^{1}$ University of Calgary, Calgary, Canada \\ ${ }^{2}$ SAIT Polytechnic, Calgary, Canada
}

\begin{abstract}
This paper presents a framework for using virtual worlds in the construction of teaching platforms for just-in-time training. In the critical economic situation that many companies are currently living, the need to update skills without leaving the workplace has become urgent. Employees are demanding training for higher performances, knowledge and skills, without requesting time to attend university, or leaving their work behind. In this context, the use of virtual worlds has become the way knowledge is shared and accessed, as virtual groups become learning communities. The potential of Second Life as a space to learn and be trained are explored. The characteristics and capabilities of virtual worlds for teaching and learning are examined, the role of the virtual tutor is analyzed, and further areas of research and development are presented.
\end{abstract}

Index Terms-just-in-time training, teaching frameworks, Second Life, virtual worlds.

\section{INTRODUCTION}

The role of education in society is changing, placing new pressures and demands on workplace training and educational institutions across the globe. Many of the increasing challenges are arising from the emerging generation of new learners who are far more proficient with emerging technologies and who are demanding that training "keep up". Also, the trend in professional society is changing. In this critical economic situation, company employees want to update skills without leaving the workplace, and without requesting time to attend university or technical institutions. In attempts to address these challenges, many companies are looking to implement just-in-time training, characterized by work-specific content, delivery only as needed and flexible training approaches and media [1]. This paper proposes that immersive three-dimensional (3D) environments are one of the technologies that lend themselves to just-in-time training.

\section{JUST-IN-TIME TRAINING}

The "just-in-time" training concept has gained attention among universities and polytechnic institutions in recent years. Research shows that $70 \%$ of the information learned on training courses is forgotten by the time it student needs it [2], [3]. Just-in-time training offers alternatives to classroom education for training those students who need the "know how" while already located in their job positions.

Just in time training occurs on the job, in the context of a particular task [1]. This new way of training clearly responds to companies' needs to have full time employees on their workplaces at all time. This means that the distance between the training need and the delivery is cut as employees receive the requested training on-the-spot, ondemand and in-context.

In current years, the use of new media and/or computer based software has provided a rich environment for justin-time training to happen. Simulations and virtual environments constitute a favorable environment to access content and training while responding to the demands of the workplace.

\section{VIRTUAL WORLDS}

Computer-based virtual environments have been a focus of research interest in recent years because of their potential applications in training, design, visualization, education and entertainment [4]. With the capability of simulating real life environments, these $3 \mathrm{D}$ virtual worlds have the potential to transform the ways in which people work and learn. As this technology allows content to be virtual, so also has it enabled virtual learner engagement and participation? Being portable and digital, virtual worlds change the ways in which learners access content, entertainment, and knowledge, erasing the physical limits of the classroom. The programmable, contextual and connectable affordances of virtual worlds [5] provide us with new and easily accessible construction and networking capabilities. In short, virtual worlds can help us traverse time and space to learn beyond physical limitations in more interactive environments.

Second Life (SL) is one of these "Internet-based virtual worlds” [6]. Originally conceived by Peter Rosedale, now the CEO and Founder of Linden Lab, this project opened its doors to the public in 2003. With more than 12 million users by 2009, SL allows users (called 'residents') interact with each other, communicate, and play in an environment that is user owned and user-created". As of December 2009, 1400 organizations including universities and Fortune 500 companies have a presence there [7], [8].

As these spaces becomes part of the global training community, innovative educators around the world are exploring how virtual worlds can serve as powerful educational tools in instructors' and students' approaches to teaching and learning. Both formal and informal education happens in SL. By formal education, we refer to classes, instruction, training and simulations. In the informal category, we include immersive museum exhibits, informal chatting on academic topics, role-playing, etc. Second Life learning uses almost all the possible forms of knowledge sharing and acquisition: networking and collaboration, in an immersive experiential and a participatory 
culture [9], [10]. Because Second Life use is not restricted to the classroom, its use in higher education and the workplace context can take the learning process beyond traditional boundaries to offer anytime / anywhere / just-intime opportunities for teaching and learning.

However, the novelty of using virtual worlds for education brings with it the challenge of developing new pedagogical understandings around the use of synthetic experiences and the educational contexts within contemporary society. There are still many questions to be answered while we explore how we can usefully expand the learning opportunities and discover the 'new' benefits of using new technologies for learning. These connections are only beginning to emerge in the literature [11]. Thus, it is important that the development of case studies using these new technologies should be accompanied with a continuous search for pedagogical models that could enrich and inform the learning experience. With this in mind, this paper offers a framework of considerations for the development of just-in-time training. The framework is illustrated here in the context of three Second Life projects: Robotics and Multimedia, New Media in a Technical Institution and Clinical Training for Third Year Medical Students.

\section{THE PROJECTS}

\section{A. Robotics and New Media}

In June 2008, a group of innovative instructors of the Robotics and Multimedia Programs at the Southern Alberta Institute of Technology (SAIT) decided to explore the possibilities of using SL for their students to learn and review the procedures happening inside these environments. Two groups of students in two different programs were targeted: the Robotics students at the School of Manufacturing and Automation, and the Multimedia students, at the School of Information Technologies. The Second Life implementation for robotics was designed to provide a virtual space where students could learn how manufacturing robots operate in an industry plant, how machines work in manufacturing, and how complex atomic systems interact with each other. For teaching new media, students use virtual equipment in Second Life to practice moving cameras, lighting sets, mixing video, and shooting videos in a customized environment

\section{B. Virtual Patient: Virtual Environments}

Healthcare education in real settings is highly opportunistic, based as it is on learners only seeing those patients who "happen" to come into the particular clinical settings. Seldom do medical students encounter the breadth of problems that are expected to build true competency. In response to this problem, the Faculties of Medicine and Education at the University of Calgary joined forces in the Virtual Patients; Virtual Environments (VPVE) project. The project purpose is to create urban and rural virtual clinics and virtual patients in Second Life to help medical students "fill the gaps".

\section{THE FRAMEWORK}

Creating learning experiences in virtual worlds relies on the usual instructional design considerations [12], [13], [14] - training needs, target audience, resources, tasks, content context, and media selection for example. However, experiences in these three projects have led to the conclusion that these are insufficient for designing in 3D immersive virtual worlds; other factors can and should be considered. The proposed 3D instructional design (3D-ID) framework (Fig. 1) for just-in-time training has six additional factors for consideration: Participation Type, Instructor Roles, Participants, Interaction, Orientation, and Virtual Tutors. These additional considerations are described and illustrated with examples based on lesson learned from the three projects.

\section{A. Types of Participation}

Sfard identifies two teaching and learning models: the "Acquisition Model" and the "Participation Model" [15]. With the Acquisition model, the focus of learning activities is on acquiring pre-specified knowledge and on developing understanding of predetermined concepts. With the Participation Model, the focus of learning activities is on becoming a member of a community of practice, learning from the community but also contributing to it. With the Acquisition Model what is to be learned is generally predetermined. In the Participation Model, the interactions that the learner contributes to may serve to change their own knowledge base and that of the community even as he or she participates [16].

Virtual worlds can be used successfully for both acquisition and participation. However, their strength lies in the participatory model; in particular, within five types of participatory activities: simulation, infrastructure exploration, organization, and design 1 . Each has its own character and affordances for learning, as described in Table 1. Moreover, because of the social networking capabilities of virtual worlds, these activities are suitable for individuals or for the collaborative groups that build community and the community knowledge base.

Across the five participation types there are implications for just-in-time training. Once developed, the virtual environments are usually "ready to go" at a moment's notice, without the problems of setup, equipment breakage and cleanup. The virtual worlds are scalable; if more people need training than physical space comfortably or functionally allows, the environments can be expanded or they can be copied and pasted to make as many instances as are required. Moreover, virtual worlds are easily modifiable, so it is easy to keep an original environment or case, and at the same time, copy and modify the case to quickly create a new and different version.

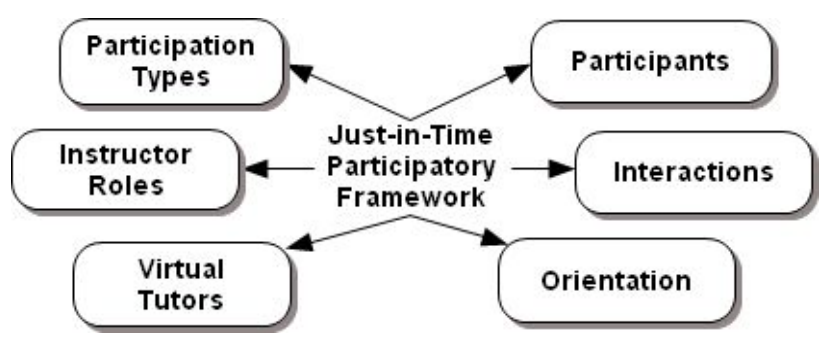

Figure 1. Framework for just-in-time training for Second Life.

${ }^{1}$ These "types" were derived some years ago during a workshop and online discussion forum, designed to explore the use of 3D immersive worlds following a participatory model. The eight educator participants and three high school participants generated 26 theoretical ideas and multiple examples of each. Thematic analysis of the ideas and examples revealed these five participatory types. 
TABLE I.

FIVE PARTICIPATION TYPES FOR VIRTUAL WORLDS

\begin{tabular}{|c|c|}
\hline Type & Description \\
\hline Simulation & $\begin{array}{l}\text { These activities model real world environments } \\
\text { and interactions with people, objects or data within } \\
\text { the synthetic virtual world. This contextualized and } \\
\text { situated [11] participatory implementation allows } \\
\text { participants to safely engage in authentic problem } \\
\text { solving, decision making, clinical reasoning, etc. }\end{array}$ \\
\hline Infrastructure & $\begin{array}{l}\text { This implementation sets up a pre-made environ- } \\
\text { ment ready to be used for instructional activities } \\
\text { primarily involved with communication - a court } \\
\text { room or a mock interview setting, for example. }\end{array}$ \\
\hline Exploration & $\begin{array}{l}\text { This implementation allows learners to explore an } \\
\text { environment - looking for workplace hazards or } \\
\text { familiarization with office layouts and supplies, for } \\
\text { example. }\end{array}$ \\
\hline Organization & $\begin{array}{l}\text { Virtual worlds offer affordances for intuitive } \\
\text { organization and display. Often, this implementa- } \\
\text { tion is associated with the logistics of training - } \\
\text { pulling together in-world and out-world database } \\
\text { resources, providing venues for displays of studio } \\
\text { work, for example. }\end{array}$ \\
\hline Design & $\begin{array}{l}\text { Virtual worlds allow instructors and developers to } \\
\text { build environments for simulations, infrastructure, } \\
\text { exploration and design, but it should be noted that } \\
\text { they also offer powerful built-in tools for learners } \\
\text { to design, prototype and build - architectures, } \\
\text { plans, fashion, for example. }\end{array}$ \\
\hline
\end{tabular}

For both of the Robotics and New Media Project, the primary participation type was simulation. Virtual classrooms and learning labs were created to simulate processes and facilitate students' interaction with technologies. The multimedia lab simulates a real stage set where students learn how to use illumination systems, for example (Fig. 2). The physics engine resident in Second Life shows lighting, shadows and color filters from lighting sources as they would appear in real life. In the Robotics classroom, students learn how to build robots by simulating the mechanical pieces to put together, the manufacturing plant, and the final movement of the mechanical robot.

For both of the Robotics and New Media Project, the primary participation type was simulation. Virtual classrooms and learning labs were created to simulate processes and facilitate students' interaction with technologies. The multimedia lab simulates a real stage set where students learn how to use illumination systems, for example (Fig. 2). The physics engine resident in Second Life shows lighting, shadows and color filters from lighting sources as they would appear in real life. In the Robotics classroom, students learn how to build robots by simulating the mechanical pieces to put together, the manufacturing plant, and the final movement of the mechanical robot.

In the Virtual Patients: Virtual Environments project, the primary participation type is also simulation, where the student physicians interact with tools and virtual patients in the context of various case clusters. However, there is also infrastructure for observation, debrief, meeting and small group discussions and organization of learning and medical resources. In addition, there are opportunities for "design" participation for both instructors and students for case development.

No matter what the participatory type implemented in face-to-face training, there is almost always a logistical requirement (e.g., setup, booking, cleaning) In virtual worlds, activity setup can be instantaeous, ready for the any time / any place demands of just-in-time training.

\section{B. Instructor's Role}

Virtual environments support a modern pedagogical model where the instructor becomes a facilitator of knowledge and is no longer the "knowledge holder". A number of researchers have looked at this framework factor.

Burkle \& Meredith examine the change from the instructor as a 'knowledge source' to a facilitator providing a conversational framework for the evolution of learning [3].

Laurillard, presents four key elements of the facilitation process. These involve both students and teachers. [17]:

a) discussion (between instructor and e student);

b) interaction (between the student and some aspect of the world defined by the instructor);

c) adaptation (of the world by instructor and action by the student) and

d) reflection (on the student's performance by instructor and student).

In the virtual Robotics lab context, instructors demonstrate how robots and manufacturing operate. Students learn while observing the procedure as it takes place synchronously with instructors and students both present in the virtual world. It is possible then for students to come back later, in an asynchronous time, and test the machines on their own.

At the virtual Multimedia lab, the instructor shows the students how they should operate a camera set: the illumination capabilities of the set, the camera settings, the video recordings, etc. Then the students operate the camera and other tools while the instructor remains as an observer, giving feedback only when students need it.

In the virtual clinics, instructors can participate in the scenarios with students and debrief performance synchronously with the student physicians and observers. Within the infrastructure of the debrief room, there is a media display panel for showing the recorded performance and an interactive whiteboard for the instructor to add just-intime notes and other instruction.

Because performance is recorded, the instructors can also debrief asynchronously. It is also possible for the instructor to monitor, facilitate and assess individual student performance via instant messaging if the instructor so desires.

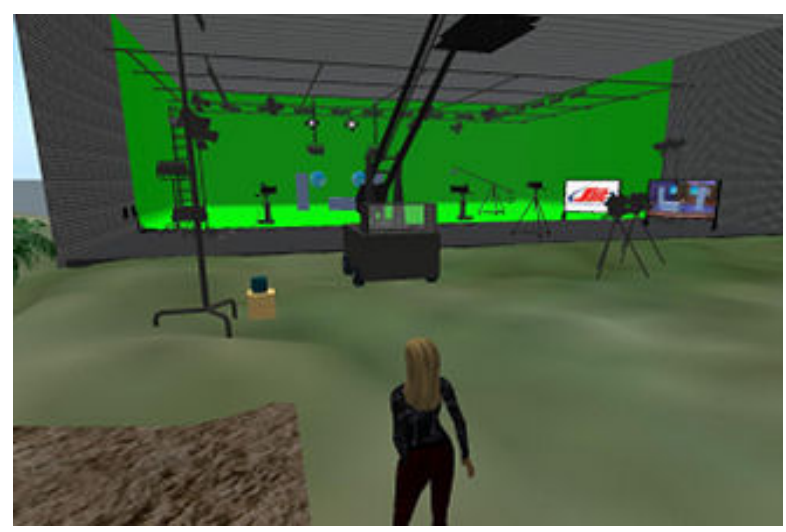

Figure 2. Simulated TV stage set for lighting simulation. 


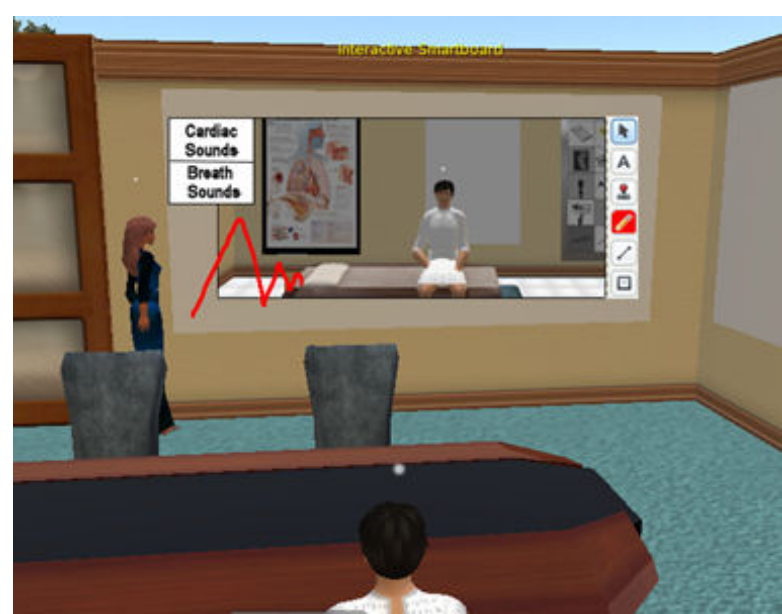

Figure 3. Debrief. Ihe instructor can debrief the student using the video captured during the case and/or an interactive Smartboard -- to draw the irregular heartbeat heard in the case, as in this example.

The use of technologies for teaching and learning should have, as one of its main goals, provision for student-centered situations, where instructors facilitate access to content in a horizontal, sharing environment. As illustrated in the examples, once the participation type is established, instructors do not need to "deliver" the instruction; instead, students interact with the learning experience framed within the virtual world environment, leaving the instructor with the freedom to act as facilitators within the simulation, infrastructure and other types, monitoring and guiding each student on an independent learning path within the larger group [18].

\section{Participants}

One interesting and useful affordance of virtual immersive worlds is the ability to change a participant's frame of reference - learning by "standing in someone else's shoes" [5]. Appearance and voice can be completely changed for role-playing any part, irrespective of gender, age, culture, or any of the other constraints that physical appearance and geographical location would normally impose in real life. Of particular interest to just-in-time training, time is the ability to provide instantaneous transformation from self to someone else by logging into a pre-designed avatar or by customizing one's own avatar's appearance with a pre-designed package. The transformation has the added advantage of placing a mask on participants, disguising them from others in a scenario and providing anonymity, if desired.

In addition to the above "inside-out" frame of reference where one participates from an ego-centric point of view, immersive worlds also offer the opportunity to synchronously observe or asynchronously review the encounter "to see ourselves as others see us". This is an "outside-in" frame of reference, where one uses a world-centric or God's eye view for locating one's self in space and situational awareness [19].

In the "inside-out" perspective of the VPVE project cases, real physicians play the roles of virtual patients while medical students log in to physician avatars. In the role of virtual patient, the real physician has a first-hand view of the student's performance for assessment; the student has a first-hand experience playing the role of physician.
The "outside in" perspective is offered in two ways. Others can peripherally participate [20] in the case because all visual and auditory cues that the virtual physician experiences during the case can also be seen and heard by the patient and by observers in an adjoining room with one-way glass. Fellow students observing the case can wrestle with the clinical reasoning alongside the student playing the role of physician (except without the ability to control interactions with the patient). In addition, because the encounter is recorded, the individual medical student alone or with the observers can be debriefed at a later time. The recordings are available in-world or from a website outside Second Life.

\section{Interactions}

Social interaction, camera view manipulation and navigation are three interaction types that are built in to Second Life, ready for just-in-time training needs that involve communication, demonstration, and moving from place to place. Participants in the world can use voice or text chat to communicate with others in the vicinity and social networks allow people to communicate with "friends" who are elsewhere in-world. Camera views include the normal ego-centric view through one's own eyes, a thirdperson "over the shoulder" view of one's own avatar as it moves through the world, and the ability to zoom in and to take a 360 degree look around objects without moving one's avatar body. Navigation is also built in using arrow keys to move one's avatar forward and back, right and left. It is also possible to fly and to "teleport" to other areas in-world.

Actions and interactions can also be programmed. In the Robotics project, students interact with robot parts to independently or collaboratively build robots (Fig 4). In the VPVE project, virtual physicians work with instruments and equipment on a Physician Interaction Panel (Fig. 5); virtual patients can initiate actions (e.g., lay down on the examination table) or animations (e.g., facial expressions, limp) using a heads-up display (HUD) of point and click icons that reflect the interaction choices.

Many tutorials for programming interactions are available online. Unfortunately, the built-in features and the programmed interactions of Second Life can both pose challenges to user orientation.

\section{E. Orientation}

One of the challenges of virtual worlds - and of simulation in general - is the time required for participant orientation of users, especially with respect to interaction.

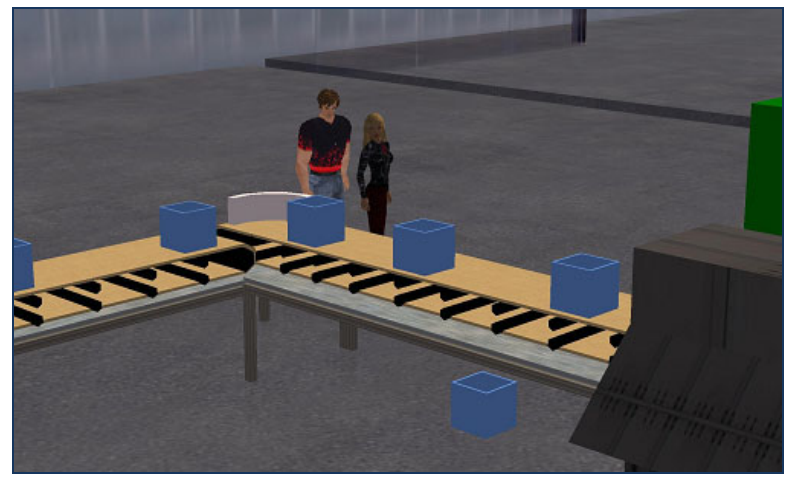

Figure 4. One of the Instructors in the Robotics Program lecturing on how things move in a virtual manufacturing band. 


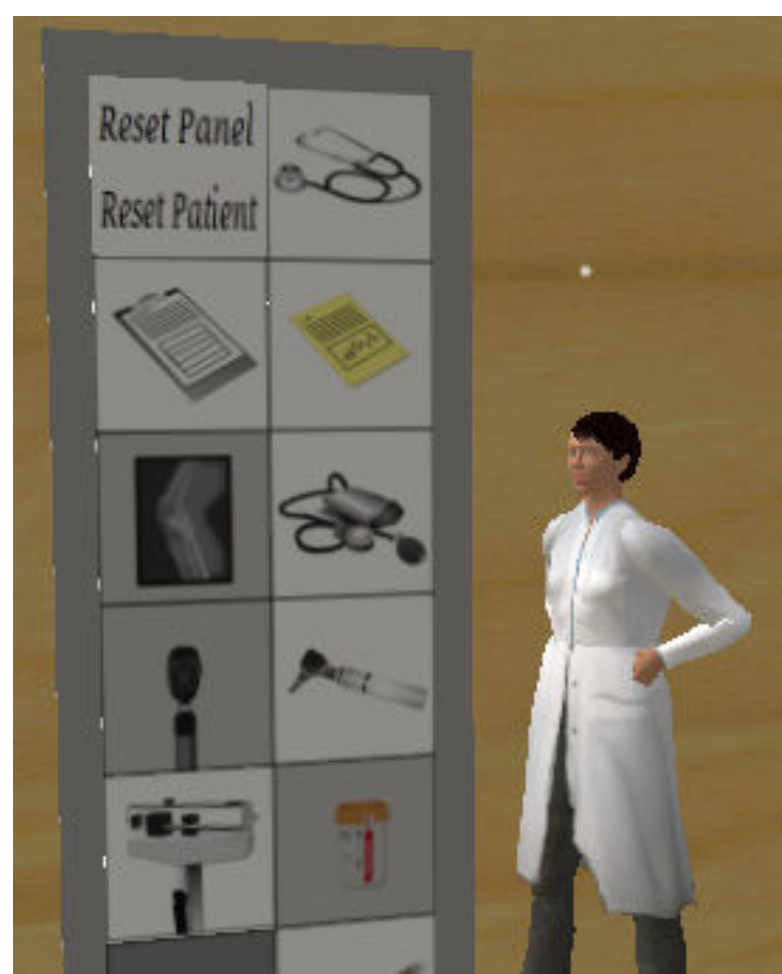

Figure 5. One of the pre-packaged avatar shells standing beside the point-and-click Physician Interaction Panel.

We know how things work in the real world but, in the virtual worlds, the most simple things takes time to learn. For example, new residents need to learn how to "be" in the avatars that represent them in the new world. They need to learn how to walk, how to talk, how to see, how to gesture, how to pick up or put down objects, how to get dressed and, generally, how to interact with the environment.

Related to the issue of orientation, a number of authors describe the need to properly train faculty when they are using technologies in teaching [21], [22], [23]. When used as a learning technology, or as a virtual place where learning takes place, SL requires, as any other learning technology, some training to use it in its full potential. The two projects handle this differently.

For the Robotics and Multimedia labs, instructors are expected to develop their own avatars, and learn how to use the virtual space to promote students' engagement. Training is provided by the Department of Faculty Development as part of instructors' academic development training. A new model, where trainees train the new trainer, was developed at the moment of this research: Experienced instructors, who have been using Second Life for two years or more, spend time in training the new users, helping them with the creation of avatars and learning objects.

The approach taken in the Virtual Patients: Virtual Environments project was to eliminate the need for an orientation as much as possible. To this end, a variety of strategies were used.

Firstly, rather than requiring students and instructors

to have their own avatars, "pre-packaged” physician, patient and observer avatars shells are available. In this case, the physician avatars are customized by the developers with gender, realistic ages and appropriate clothing.
They are also packaged with the ability to interact with the Physician Interaction Panel (Fig. 5). Patients avatars, on the other hand, are packaged with gender, age, clothing, symptoms, pathology as represented in a patient chart, disease-related media, and gestures in a Heads up Display or HUD. For both the physician and the patient avatars, the user simply logs in with the name and password of the desired avatar and (s)he is "dropped" into the prepackaged shell, ready to engage in the simulation.

Secondly, both the physicians and the patients have point-and-click interfaces that allow them to interact with each other, with tools, with furniture and with other objects in the environment. As a result, the initial orientation for simulation consists of a basic “once-through" familiarization of what is available and what to expect.

In these ways, the time needed for just-in-time instruction efficiently used and cognitive load is focused on the important learning to be done.

\section{F. Virtual Tutors}

Whenever teaching or training is part of a scenario, the instructional designer or instructor should be aware of the "what if they don't understand?" or "What if they don't get it?" situations. This attention to "negative space" drives the need for instructional support or "scaffolding" in any training. First conceived by Bruner in the context of language acquisition by children [24], scaffolding should only be available if needed; it should not be used to "overcontrol" the learner, and, like real-life construction scaffolding, it eventually needs to be removed [25].

Scaffolding tends to be used at the beginning of learning any particular domain, when learners require a good deal of support. However, virtual worlds tend towards more mature domain learning, when students are more familiar with the basics and are now ready to fit the pieces together in more authentic environments. This poses a challenge as to where and how in the virtual environment to provide the scaffolding that might (or might not) be needed. Virtual tutors offer a reasonable way of providing instructional support for learning in virtual words.

Virtual tutors, also called pedagogical agents, take on many forms, several of which are described here [26]:

a) Virtual tutors can take the form of online support entities or electronic performance support systems (EPSS). These are often implemented within help menus where a search engine interface guides the interaction

b) Another form can be video characters that help the user to navigate through a website. In virtual worlds, these often act in ways similar to the audio guides available at museums. These provide context-specific help and information on-demand or automatically as a learner triggers proximity detectors forparticular places or objects. These can also be activated on demand from the learner

c) Virtual tutors can act as learning agents [27] or as learning companions in the form of computer characters. In $3 \mathrm{D}$ environments, these are often implemented as non-playing characters (NPC's) or chatbots. With learning companions, interactions tend to be typed conversations, supported by rudimentary (or more sophisticated) natural language processing systems to decipher the request and expert systems to determine a suitable answer. 
The Robotics and New Media projects did not implement virtual tutors. Instead, the instructors act as tutors, interacting with students in the form of avatars to provide the instructional support.

The Virtual Patient: Virtual Environments project took a different approach from the virtual tutors described. Here, virtual tutors were included as experts' perspectives on the various aspects of the different cases. These perspectives are gathered and constructed from recording subject matter experts (i.e., senior physicians) as they go though each case, seeing it for the first time as a "real" patient encounter. For now, physicians also play the part of the patient avatar. The captured virtual tutor expertise included what questions the experts would ask and why, which tests they would order or perform and why, how they would interpret the test and lab results and why, which differential diagnoses they would consider and why, and, finally, which diagnosis would be the final determination.. Students physicians can then access these granular perspectives for each case on demand.

As expected, different experts follow different paths even when they are all working the same case and students have access to these different ways of thinking for each case. This approach to virtual tutors is pedagogically strong. It helps to ensure that students are not forced into a single, reductionist "right way" of thinking about practice and it provides opportunities for developing cognitive flexibility [28] - i.e., it promotes the ability to flexibly restructure one's knowledge, in adaptive response to situational demands in ill-structured domains such as medicine. The multiple perspectives offered by this approach to virtual tutors allows students to access different ways of looking at the case, helping them to construct their own knowledge and providing a basis for further exploration and questioning with the instructors during debrief. In addition, as the students' confidence and skills improve, the expert virtual tutors act as a self-assessment mechanism. Finally, this approach offers a relatively easy-toimplement way of including most of the scaffolding features proposed by Wood, Bruner, and Ross [29]:

- The approach reduces the "degrees of freedom", simplifying the task) by showing correct choices and procedures;

- it provides "direction maintenance" as the tutor shows the learner how to keep the focus on the diagnostic objective;

- it "marks critical features" so that the learner can discern for him-or herself any discrepancies between personal performance and expert performance;

- it allows for "frustration control" to keep the learner from getting "stuck" and

- it offers “demonstrations" or ideal modeling of the act to be performed.

In all of the different virtual tutor forms, the electronic, always-there nature of virtual tutors off-loads some of the need for instructors and helps to meet the "on demand" requirement of just-in-time training.

\section{FRAMEWORK AND BUSINESS / INDUSTRY TRAINING}

Adding to the examples given above, the just-in-time training framework can also be utilized in business and industry. The following only scrape the surface of possibilities:
- Infrastructure for meetings, conferences, brainstorming sessions and more traditional "classroom" training can be set up, especially for those participants who are geographically separated.

- New employees and those from other branches can easily familiarize themselves with any company venue.

- Before business trips, employees can drop in for intercultural training or teleport to other-language SL areas to practice their language skills with native speakers.

- SL venues can be used to try out new workflows and drill new procedures (e.g. security deployment, emergency planning).

- Interpersonal training (e.g., sales calls, customer service, team training) can be simulated in authentic environments.

- Employees can practice responses to accidents, hazardous materials and other situations that are difficult, dangerous or costly to simulate in the real world.

As in any instructional situation with any medium, it should be noted that the quality of the earning experience in a 3D immersive virtual world such as Second Life will only be as good as the instructional design that frames the training.

\section{CONCLUSION}

The framework for building training in Second Life takes advantage of the affordances available in immersive $3 \mathrm{D}$ virtual worlds with a number of positive implications for just-in-time training. Five of these are summarized here. Firstly, the any time, any place nature of the virtual environments lends itself to the "on demand" requirements of just-in-time training. Secondly, participation types offer flexible approaches to instructional activities that can be tailored to meet specific workplace training needs, another requirement that characterizes just-in-time training. Thirdly, changing instructor roles in virtual environments allow instructors to focus on individual development, which benefits both the individual and the workplace. Fourthly, it is possible to minimize time and costs for student travel, time off work, and orientation while maximizing student learning with authentic and situated training scenarios. Finally, virtual tutors can provide the required scaffolding while off-loading instructor time and effort.

As we witness the impact of virtual worlds such as Second Life in the teaching and learning experience, we also have to consider the fact that, at present time, this is only the 'tip of the iceberg'. Future developments in virtual environments will make possible what today is not even thinkable. Further research on Second Life possibilities for just-in-time learning will need to take into account the active participation of workplace learners, as they build and develop their own learning scenarios in Second Life, and will need to approach teaching and learning as a dynamic process, where both learners and instructors interact horizontally, in the same 'virtual world', in the construction of knowledge. 


\section{ACKNOWLEDGMENT}

The authors would like to thank the Undergraduate Medical Education at the University of Calgary and acknowledge Craig Maynard (Instructor at the School of Manufacturing and Automation), Dick Bourne (Academic Chair of the New Media Program) and Dr. Doug MacLachlan (Faculty Development Services) from the SAIT Polytechnic.

\section{REFERENCES}

[1] M.J. Jones, “Just-in-time Training”, Advances in Developing Human Resources, vol3, no. 4, pp. 480-487, November 2001. doi: $10.1177 / 15234220122238409$

[2] L. Derek, "Delivering open access: from promise to practice", Ariadne, Issue 46, January. Available online: http://www.ariadne.ac.uk/issue46/law/, January, 2006.

[3] M. Burkle and S. Meredith, S , Building bridges between University and Industry: theory and practice. Education \& Training, Vol. 50 No. 2, 199-215, 2008.

[4] B. Park and R. Wakefield R. "Evolution of visualization technology in construction: Current practices and future implications, and their genuine role.” in Proceedings of the Third International Conference on Information Systems in Engineering and Construction, Orlando, FL., 2003

[5] G. Kopp and M. Burkle, "Web 2.0 and 3.0 affordances for second generation virtual patients,” Journal of Computers in Healthcare, vol.1, [in press].

[6] Second Life. Wikipedia, Online. Retrieved Mar 28, 2010 from http://en.wikipedia.org/wiki/Second_Life

[7] L.Y. Qing. “Businesses Get a Second Life,” ZDNet Asia, Online. Retrieved May 1, 2010 http://www.zdnetasia.com/businesses-geta-second-life-62060033.htm

[8] Life Work: About Us. Online. Retrieved Mar 28, 2010 from http://work.secondlife.com/en-US/about/.

[9] M.S. Conklin, "101 Uses for Second Life in the College Classroom". Research Paper. online retrieved on June 28, 2010: http://citeseerx.ist.psu.edu/viewdoc/download?doi=10.1.1.133.958 8\&rep=rep1\&type=pdf, 2007

[10] A. Rothery, Virtual worlds. Paper presented at the European University Information Systems SL conference. Online retrieved on Feb 10, 2008: http://events.um.edu.mt/euniseltf/virtualworlds.pdf, 2005

[11] L. Kervin, D. Reid, J. Vardy and C. Hindle. “A partnership for iPod pedagogy: Using technology of millennial learners across educational contexts" in Proceedings of the $23^{\text {rd }}$ Annual Ascilite conference. Sydney: 2006 Australia. Retrieved Dec 12, 2008, from:http://www.ascilite.org.au/conferences/sydney06/proceeding/ pdf_papers/p111.pdf

[12] W.J. Rothwell and H.C. Kazanas, Mastering the Instructional Design Process: A Systematic Approach (Fourth Edition), San Francisco: Pfeiffer, 2008.

[13] J.E. Kemp, G.R. Morrison and S.M. Ross, Designing Effective Instruction (Fourth Edition), Hoboken, N.J: John Wiley \& Sons, Inc., 2004.

[14] P.L. Smith and T.J. Ragan, Instructional Design (Third Edition), Hoboken, N.J.: John Wiley \& Sons, 2005.
[15] A. Sfard, "On two metaphors for learning and the dangers of choosing just one'. Educational Researcher, vol. 27, no. 2, pp.413, 1998.

[16] J.S. Brown, A. Collins, and P. Duguid, (1989). Situated cognition and the culture of learning. Educational Researcher, vol. 18, no. 1, pp. 32-41.

[17] D. Laurillard, D. Rethinking University Teaching. London: Routledge, 2002. doi:10.4324/9780203304846

[18] V. Uskov and L. Sheremetov, L, "Interlabas: The Web-lecturing Multiagent-Based Tool. Proc of IASTED International Conference on Artificial Intelligence and Soft Computing. Cancun, Mexico, 2001.

[19] C.D. Wickens and P. Baker, "Cognitive Issues in Virtual Reality”, Human Perception and Performance Technical Report, 1995.

[20] J. lave and E. Wenger, Situated Cognition: Legitimate Peripheral Participation, New York, NY: Cambridge University Press, 1991.

[21] T. Bates, Managing Technological Change. Strategies for college and university leaders. San Francisco: Jossey-Bass, 2000.

[22] Hughes, The Role of Teacher Knowledge and Learning Experiences in Forming Technology-Integrated Pedagogy. Journal of Technology and Teacher Education, Vol 13, Issue 2, April 2005.

[23] M.J. Koehler and P. Mishra,. "What happens when teachers design educational technology?” Journal of Educational Computing Research, Vol. 32, (2), 131- 152, 2005. doi:10.2190/0EW7-01WBBKHL-QDYV

[24] J. Bruner, ”The ontogenesis of speech acts.”, Journal of Child Language, vol. 2, pp. 1-40, 1975. doi:10.1017/S03050009000 $\underline{00866}$

[25] D. Wood, “Social interaction as tutoring” in Interaction in Human Development, M. H. Bornstein and J. S. Bruner, Eds., Hillsdale, NJ: Lawrence Elbaum Associates, pp. 59-80, 1989.

[26] U. Spierling, Learning with Digital Agents - Integration of Simulations, games and storytelling" in Digital Based Learning Proceedings of the $4^{\text {th }}$ International Symposium, M. Burmester aD. Gerhard and F. Thiessen, Eds, Stuttgart Media University, 2005

[27] A. de Antonio Jiménez and B.Troncoso Pantoja, ”Scaffolding Tutoring Strategy on Virtual Environments for Training", Ingeniare. Revista chilena de ingeniería, vol. $16 N^{\circ}$ 2, 2008

[28] R.J. Spiro, R.L.Coulson, P.J.Feltovich and D.Anderson, D. Cognitive flexibility theory: Advanced knowledge acquisition in illstructured domains" in Proceedings of the 10th Annual Conference of the Cognitive Science Society, V. Patel, Ed., Hillsdale, NJ: Erlbaum, 1988.

[29] D. Wood, J.S. Bruner and G. Ross. "The role of tutoring in problem solving”. Journal of Child Psychology and Psychiatry. Vol.17 Issue 2, pp. 89-100. April 1976. doi:10.1111/j.1469-7610.19 76.tb00381.x

\section{AUTHORS}

G. Kopp is with the University of Calgary, Calgary, AB, T2N 1N4 Canada (e-mail: gkopp@ucalgary.ca)

M. Burkle is with SAIT Polytechnic Calgary, AB, T2M 0L4 Canada (e-mail: Martha.Burkle@sait.ca)

This article was modified from a presentation at the ICELW2010 Conference in New York, USA in June 2010. Submitted July 28 ${ }^{\text {th }}, 2010$. Published as resubmitted by the authors July 29th, 2010. 